Original Research Articles

\title{
The Association between Asphyxia and Interleukin (IL)-6 and IL-1ß Levels in Neonates
}

\author{
Nenden Nursyamsi Agustina1*, Muhammad Sholeh Kosim2 \\ ${ }^{1}$ Department of Pediatrics, Faculty of Medicine, Universitas Jenderal Soedirman/Prof. Dr. Margono Soekarjo \\ Hospital, Purwokerto, Indonesia \\ ${ }^{2}$ Division of Neonatology, Department of Pediatrics, Faculty of Medicine, Universitas Diponegoro/ Dr. Kariadi \\ General Hospital, Semarang, Indonesia
}

\section{Article Info}

History

Received: 06 June 2021

Accepted: 12 Aug 2021

Available: 31 Aug 2021

\begin{abstract}
Background: Neonatal asphyxia is a respiratory failure during and just after birth. It can cause morbidity and mortality in neonates. Interleukin (IL)- 6 and IL- $1 \beta$ are inflammatory cytokines produced by neuronal cells in early response to brain injury due to asphyxia. However, their role in neonatal asphyxia is remain elusive.

Objective: To determine the association between asphyxia and serumIL- 6 and IL- $1 \beta$ levels in neonates.

Methods: Across-sectional study was conducted on neonates diagnosed with moderate to severe asphyxia who hospitalized at the Dr. Kariadi General Hospital Semarang Indonesia from December 2013 to May 2014. The subjects were examined for serum IL- 6 and IL-1 $\beta$. Blood samples were obtained from umbilical vein in the first 24 hours of life. Serum IL-6 and IL-1 $\beta$ levels were measured using immunoassay. Dependent variable were IL-6 and IL-1 $\beta$ level. Bivariate analysis was performed using chi-square test, for the assessment of the association between dependent and independent variables. A p-value of less than 0.05 was considered statistically significant.

Result: A total of 54 subjects were enrolled in this study. No significant difference between moderate and severe asphyxia neonatesin term of sex, birthweight, type of delivery, neonate's mother age, gestational age, and parity. Levels of IL- 6 and IL- $1 \beta$ levels wereincreased significantly in both moderate and severe asphyxiagroups, and the levels were significant higher in the severe asphyxia than that of in the moderate, $p=0.003$ and $p=0.007$, respectively.

Conclusion: There was association between asphyxia and IL- 6 and IL-1 $\beta$ levels in neonates.IL-6 and IL-1 $\beta$ levels were increased in neonates with moderate and severe asphyxia, with extend of increase was significant higher in the later.
\end{abstract}

Key-words: Neonatal asphyxia; IL-6; andIL-1 $\beta$

Permalink/ DOI: https://doi.org/10.14710/jbtr.v7i2.11524

\section{INTRODUCTION}

Neonatal asphyxia is a condition of respiratory failure during and just after birth. It is a common cause of morbidity and mortality in neonate with an estimated incidence 1 to 6 per 1,000 baby births and about 4 million neonates around the world died from severe asphyxia each year. ${ }^{1,2}$

\footnotetext{
* Corresponding author:

E-mail: nursyamsi.agustina@unsoed.ac.id (Nenden Nursyamsi Agustina)
}

The imbalance between fetal and maternal blood supply causes oxygen supply disturbance and leads to hypoperfusion, autoregulation change, and hypoxia. Severe hypoxemia decreases adequate oxygen supply to several organs including brain, lung, heart, kidney, gastrointestinal tract, hematologic system, and muscle, and thus may cause organ damage or even death. ${ }^{3-6}$

Asphyxia can cause early inflammatory response and significant brain injury in neonates. White matter brain injury is the main cause of neurodevelopmental disorder and long-term disability. An animal experimental study 
showed that cytokine plays a role in causing hypoxicischemic disorder, ${ }^{7}$ including in response to brain injury. ${ }^{8}$

Pro-inflammatory cytokines increase during acute phase after hypoxia. ${ }^{9}$ Interleukin (IL)- 6 and IL- $1 \beta$ are pro-inflammatory cytokines produced by astroglia, microglia, and progenitor cells oligodendrocytes in central nervous system ${ }^{10}$ and released in early response of cells injury and inflammation. ${ }^{9}$ The involvement of IL6 in a clinical study including preterm newborns in the cascade of cerebral injury during perinatal period may occurred with or without infection. ${ }^{11}$ IL-6 level in serum and brain tissues in the hypoxic-ischemic neonatal rat was significantly increased by 6 hours, reached peak by 24 hours post injury and declining to the baseline level by 7 days. The study was conducted in rats model underwent left common carotid artery ligation followed by $8 \% \mathrm{O} 2$ and $92 \% \mathrm{~N} 2$ exposure to become hypoxicischemic model. ${ }^{12}$ The role of IL-6 in animal model in response to the ischemic-hypoxic after ischemichypoxic insult remains unclear. A study in animal model of myocardial infarction showed that IL-6 causes myocyte damage mediated by neutrophil. ${ }^{13}$ On the other hand, the role of anti-inflammatory of IL-6 may have opposite effect of IL-1 $\beta$. Recently, IL-6 was found having suppression effect on demyelination ${ }^{14}$ and reducing toxicity of $\mathrm{N}$-methyl-D-aspartic acid receptor and ischemic damage in vivo in animal. ${ }^{15}, 16$

The mechanism and inflammatory mediator which involve in this process remain unclear. Thus, in this study, we investigated the IL- 6 and IL- $1 \beta$ levels in moderate and severe neonatal asphyxia, and found that their levels were increased with extend of increase was significant higher in severe asphyxia. This study examined serum IL- 6 and IL- $1 b$ from umbilical cord of neonates in all gestational age, in one frame of study in early 24 hours of life. It therefore enables to identify early the severity of hypoxic-ischemic neonatal patients. The study can open possibility to use these biomarkers for evaluating the treatment and predict the outcome.

\section{MATERIAL AND METHODS}

This was analytic observational study with a crosssectional design. Fifty-four neonates with moderate to severe asphyxia who hospitalized in the Dr. Kariadi Hospital from December 2013 to May 2014 were enrolled the study. The inclusion criteria for the study sample were neonates with moderate and severe asphyxia and the parents agreed the informed consent. Patients with sepsis or infection, suffered from major congenital disorders, congenital heart disease, anemia, and their mother suffered from infection were excluded from the study. Subjects were selected with consecutive sampling. This study received ethical approval from the Ethic Committee of Faculty of Medicine Universitas Diponegoro/ Dr. Kariadi Hospital, and conformed to the principles outlined in the Declaration of Helsinki. ${ }^{17}$ All legal guardians of the subjects have provided written consent to participate in the study.

The subjects were examined for serum IL- 6 and IL$1 \beta$. Blood samples were obtained from umbilical vein in the first 24 hours of life. Serum IL-6 and IL-1 $\beta$ levels were measured using ELISA in GAKI Laboratory of Universitas Diponegoro University. ELISA kits used for
IL-6 and IL-1b examination were commercial kits purchased from Elabscience (Texas, USA).

All study variables were described based on their measurement scale. Categorical data were described using absolute and relative frequencies (percentage), while numerical data were described using mean and standard deviation. To assess the association between dependent and independent variables, bivariate analysis using Chi-square test was conducted.P-value $<0.05$ was considered as statistically significant. Mann Whitney U test was used as alternative test when the conditions for applying Chi-Square test cannot be fulfilled.
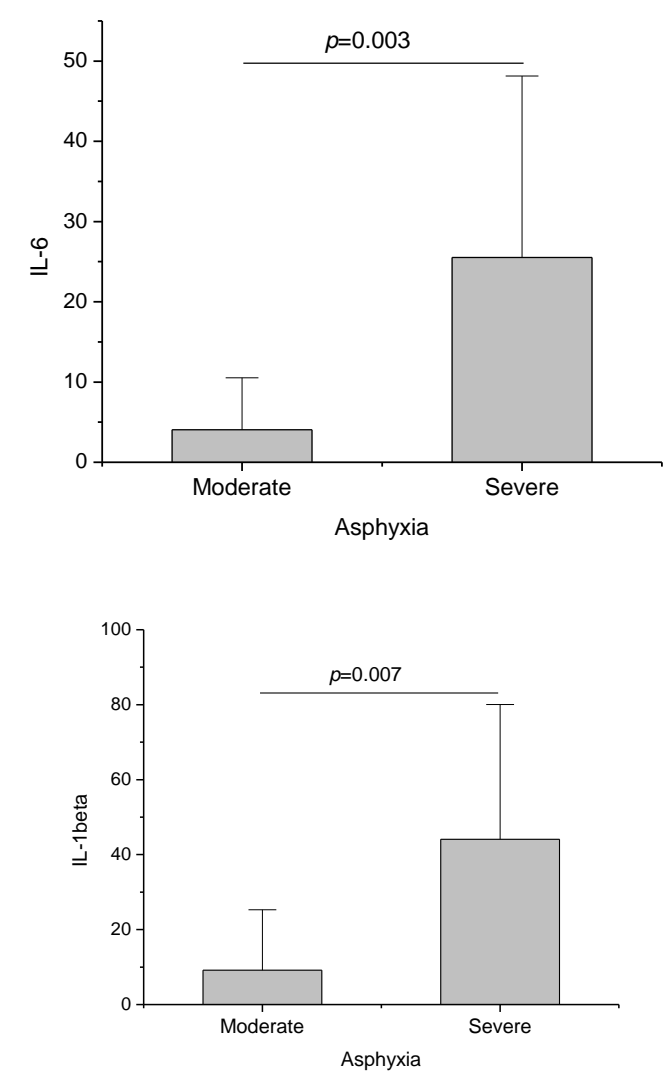

Figure 1. Levels of IL-6 (upper panel) and IL-1 $\beta$ (lower panel) $(\mathrm{pg} / \mathrm{mL})$ in the moderate and severe asphyxia neonates. Mann Whitney test was used for statistical analysis.

\section{RESULTS}

A total of 54 patients were enrolled in this study. Subject characteristics were showed in Table 1. There were no significant differences between moderate and severe asphyxia neonatesin sex, birthweight,type of delivery, mother age, gestational age, and parity.

Table 2 showed that IL-6 level in severe asphyxia was significantly higher than moderate asphyxia $(p<0.001$; $\mathrm{PR}=24.0$ (95\%CI $4.448-129.49)$. The mean of IL-6 was also significant higher in the severe asphyxia ( $p=0.003$, Figure 1A). The cutoff point between normal and abnormal values of IL- 6 was $10.2 \mathrm{pg} / \mathrm{mL} .{ }^{18}$ The mean of

IL-1 $\beta$ was higher significantly in the severe asphyxia than that of the moderate ( $p=0.0 \mathrm{~s} 07$, Figure $1 \mathrm{~B})$. Table 3 showed that IL-1 $\beta$ level in severe asphyxia was also higher significantly ( $p=0.003 ; \mathrm{PR}=5.786$ (95\%CI 1.706 19.621). The cutoff point between normal and abnormal values of IL- $1 \beta$ was $11.7 \mathrm{pg} / \mathrm{mL} .{ }^{19}$ 
Table 1. Subject Characteristics

\begin{tabular}{|c|c|c|c|c|c|c|}
\hline \multirow{3}{*}{ Variables } & \multicolumn{4}{|c|}{ Grade of asphyxia } & \multirow{3}{*}{$p$} & \multirow{3}{*}{ PR (CI 95\%) } \\
\hline & \multicolumn{2}{|c|}{ Severe (20) } & \multicolumn{2}{|c|}{ Moderate (34) } & & \\
\hline & n & $\%$ & $\mathbf{N}$ & $\%$ & & \\
\hline \multicolumn{7}{|l|}{ Sex } \\
\hline Male & 13 & 65 & 13 & 38.2 & $0.057^{€}$ & $3.0(0.950-9.475)$ \\
\hline Female & 7 & 35 & 21 & 61.8 & & \\
\hline \multicolumn{7}{|l|}{ Birth weight } \\
\hline$<2500$ gram & 8 & 40 & 19 & 55.9 & & \\
\hline$\geq 2500$ gram & 12 & 60 & 15 & 44.1 & $0.260^{\epsilon}$ & $0.526(0.171-1.616)$ \\
\hline \multicolumn{7}{|l|}{ Delivery } \\
\hline Non-spontaneous & 13 & 65 & 21 & 61.8 & $0.812^{€}$ & $1.150(0.364-3.631)$ \\
\hline Spontaneous & 7 & 35 & 13 & 38.2 & & \\
\hline \multicolumn{7}{|l|}{ Mother's age } \\
\hline Risky age & 6 & 30 & 10 & 29.4 & $0.964^{\epsilon}$ & $1.029(0.307-3.442)$ \\
\hline Un risky age & 14 & 70 & 24 & 70.6 & & \\
\hline \multicolumn{7}{|l|}{ Gestasional age } \\
\hline Aterm & 9 & 45 & 15 & 44.1 & $0.950^{\epsilon}$ & $1.036(0.341-3.148)$ \\
\hline Preterm/posterm & 11 & 55 & 19 & 55.9 & & \\
\hline \multicolumn{7}{|l|}{ Parity } \\
\hline Primiparity & 15 & 75 & 25 & 73.5 & $0.905^{€}$ & $1.080(0.304-3.834)$ \\
\hline Multiparity & 5 & 25 & 9 & 26.5 & & \\
\hline
\end{tabular}

${ }^{\epsilon}$ Pearson Chi Square test

\section{DISCUSSION}

This was a cross sectional study investigated IL-6 and IL-1 $\beta$ level in neonatal asphyxia. According to the ICD-10 categories, neonatal asphyxia is classified by clinical signs and a 1-minute APGAR score category. When the 1-minute APGAR score is 0-3, it is classified as severe asphyxia. While mild and moderate asphyxia is classified when the 1-minute APGAR score is 47. ${ }^{1}$ This study showed that IL-6 and IL-1 $\beta$ level significantly increased in both moderate and severe asphyxia. Asphyxia affords to activate immune system because of hypoxic-ischemic injury. ${ }^{20}$ IL- 6 and IL- $1 \beta$ are proinflammatory cytokine released in acute phase of inflammatory response in response to hypoxic-ischemic brain injury. ${ }^{21-23}$

There were potential markers as predictive factors of abnormal outcome in asphyxia. The markers were IL-6, IL-1 $\beta$, and neuron specific enolase (NSE). ${ }^{24}$ Asphyxia can cause cells damage if reoxygenation isn't supplied properly. ${ }^{25}$ In animal study, asphyxia reduced survival rate. $^{26,} 27$ IL-6 and IL-1 $\beta$ were negative predictor for outcome in asphyxia. ${ }^{12,19}$

Our study showed that IL-6 level significantly increased in both moderate to severe asphyxia. A study reported that level of serum IL-6 elevated significantly in neonates suffered from asphyxia and developed to hypoxic-ischemic encephalopathy (HIE) compared to normal group. IL-6 level was predictor for bad outcome in HIE. ${ }^{28}$
Measurement of IL-6 level in umbilical cord neonates suffered from asphyxia could predict negative outcome of asphyxia. Median value of IL-6 level in neonates with asphyxia that developed to be HIE increased 376-fold higher than normal group. The value increased 5,5-fold higher in neonates with asphyxia who didn't suffer from HIE than normal group. ${ }^{9,18}$

IL-6 level significantly increased in first day of neonatal asphyxia compared to control group and associated with severity of asphyxia. The elevation of IL6 level indicated that this cytokine was potential inflammatory marker of asphyxia. IL-6 level decreased in third day of asphyxia. ${ }^{29}$ IL-6 level was associated with the time of handling sample. Elevation of IL- 6 level in median value of 17,5 hours after asphyxia and the level decreased in median value of 36 hours. ${ }^{30}$

IL-1 $\beta$ level in our study increased in both moderate and severe asphyxia. IL-1 $\beta$ level was associated with stage of asphyxia. ${ }^{31}$ Level of IL-1 $\beta$ in severe asphyxia significantly higher than moderate asphyxia. ${ }^{32}$ IL- $1 \beta$ is cytokine released by mononuclear cells and macrophages in response to infection and tissue injury. IL- $1 \beta$ level in neonates with asphyxia significantly increased in the first life after injury compared to control group and it was associated with poor prognosis. ${ }^{28}$

IL-1 $\beta$ level increased during acute phase of inflammation (1-12 hours) after hypoxic-ischemic injury. An animal study showed that proinflammatory cytokines induced brain damage. IL-1 injection led to neuronal

Tabel 2. IL-6 level in moderate and severe asphyxia

\begin{tabular}{|c|c|c|c|c|c|c|}
\hline \multirow{3}{*}{ Grade of Asphyxia } & \multicolumn{4}{|c|}{ IL-6 (pg/mL) } & \multirow{3}{*}{$p$} & \multirow{3}{*}{ PR (Cl 95\%) } \\
\hline & \multicolumn{2}{|c|}{$>10.2$} & \multicolumn{2}{|c|}{$\leq 10.2$} & & \\
\hline & $\mathrm{n}$ & $\%$ & $\mathbf{n}$ & $\%$ & & \\
\hline Severe & 12 & 85.7 & 8 & 20 & $0.000 * €$ & $24.0(4.448-129.49)$ \\
\hline Moderate & 2 & 14.3 & 32 & 80 & & \\
\hline
\end{tabular}

${ }^{*} p<0.05,{ }^{€}$ Pearson Chi Squarec 
Tabel 3. IL-1 $\beta$ level in moderate and severe asphyxia

\begin{tabular}{|c|c|c|c|c|c|c|}
\hline \multirow{3}{*}{ Grade of asphyxia } & \multicolumn{4}{|c|}{$\mathrm{IL}-1 \beta(\mathrm{pg} / \mathrm{mL})$} & \multirow{3}{*}{$p$} & \multirow{3}{*}{ PR (Cl 95\%) } \\
\hline & \multicolumn{2}{|c|}{$>11.7$} & \multicolumn{2}{|c|}{$\leq 11.7$} & & \\
\hline & $\mathbf{n}$ & $\%$ & $\mathbf{n}$ & $\%$ & & \\
\hline Severe & 12 & 63.2 & 8 & 22.9 & $0.003^{* €}$ & $5.786(1.706-19.621)$ \\
\hline Moderate & 7 & 36.8 & 27 & 77.1 & & \\
\hline
\end{tabular}

$* p<0.05,{ }^{€}$ Pearson Chi Square

death and delayed myelinization in mice babies. A review in Italia showed that IL- $1 \beta$, TNF- $\alpha$, and neuron specific enolase (NSE) were potential biomarker of brain damage in neonatal asphyxia. ${ }^{28,33}$

Asphyxia led to poly (ADP-ribose) polymerase-1 $(P A R P-1)$ overactivity causing energy demand elevation, metabolic failure and decreasing $\mathrm{NAD}^{+}$, activation of NF-kB signaling pathway subunit p65, increased IL- $1 \beta$ and TNF- $\alpha$, and other proinflammatory mediators so and finally it induced cells death in mesencephalon of mice with asphyxia. PARP-1 activity increased immediately after asphyxia. It reached maximum level during 1-8 hours after insult. ${ }^{34}$ Elevation of IL-1 $\beta$, IL- 6 , and TNF- $\alpha$ in liquor cerebrospinal (LCS) of neonates with asphyxia who developed to be HIE. IL$1 \beta$ level in LCS was associated with poor outcome in neonates with asphyxia. ${ }^{35}$

\section{CONCLUSION}

There is association between asphyxia and IL-6 and IL- $1 \beta$ levels in neonates.IL- 6 and IL- $1 \beta$ levels increase in neonates with moderate and severe asphyxia, with extend of increase is significantly higher in the later.

\section{ACKNOWLEDGMENTS}

We would like to say thank you very much to Pediatrics Department of Faculty of Medicine University Diponegoro and Dr. Kariadi Hospital and who supported in the research.

\section{REFERENCES}

1. Aslam HM, Saleem S, Afzal R, Iqbal U, Saleem SM, Shaikh MW, et al. Risk factors of birth asphyxia. Ital J Pediatr. 2014;40:94.

2. Antonucci R, Porcella A, Pilloni M. Perinatal asphyxia in the term newborn. Journal of Pediatric and Neonatal Individualized Medicine. 2014;3(2):114.

3. Thompson L, Crimmins S, Telugu B, Turan S. Intrauterine hypoxia: clinical consequences and therapeutic perspectives. Research and Reports in Neonatology. 2015.

4. Ekwochi U, Asinobi NI, Osuorah CD, Ndu IK, Ifediora C, Amadi OF, et al. Incidence and Predictors of Mortality Among Newborns With Perinatal Asphyxia: A 4-Year Prospective Study of Newborns Delivered in Health Care Facilities in Enugu, South-East Nigeria. Clin Med Insights Pediatr. 2017;11:1-10.
5. Abdo RA, Halil HM, Kebede BA, Anshebo AA, Gejo NG. Prevalence and contributing factors of birth asphyxia among the neonates delivered at Nigist Eleni Mohammed memorial teaching hospital, Southern Ethiopia: a cross-sectional study. BMC Pregnancy Childbirth. 2019;19(1):536.

6. Polglase GR, Ong T, Hillman NH. Cardiovascular Alterations and Multiorgan Dysfunction After Birth Asphyxia. Clin Perinatol. 2016;43(3):469-83.

7. Chalak LF, Laptook AR, Perlman JM, Garcia D, Ramilo O, Wyckoff MH. Immediate proinflammatory cytokine response associated with asphyxia and volume infusions in a neonatal piglet model. Journal of Neonatal-Perinatal Medicine. 2008;1:69-75.

8. Li B, Concepcion K, Meng X, Zhang L. Brainimmune interactions in perinatal hypoxic-ischemic brain injury. Prog Neurobiol. 2017;159:50-68.

9. Boskabadi H, Moradi A, Zakerihamidi M. Interleukins in diagnosis of perinatal asphyxia: A systematic review. Int $\mathbf{J}$ Reprod Biomed. 2019;17(5):303-314.

10. Erta M, Quintana A, Hidalgo J. Interleukin-6, a major cytokine in the central nervous system. Int J Biol Sci. 2012;8(9):1254-66.

11. Szpecht D, Wiak K, Braszak A, Szymankiewicz M, Gadzinowski J. Role of selected cytokines in the etiopathogenesis of intraventricular hemorrhage in preterm newborns. Childs Nerv Syst. 2016;32(11):2097-103.

12. Li S-j, Liu W, Wang J-1, Zhang Y, Zhao D-j, Wang $\mathrm{T}-\mathrm{j}$, et al. The role of TNF- $\alpha$, IL-6, IL-10, and GDNF in neuronal apoptosis in neonatal rat with hypoxicischemic encephalopathy. European Review for Medical and Pharmacological Sciences. 2014;18(6):905-9.

13. Puhl SL, Steffens S. Neutrophils in Post-myocardial Infarction Inflammation: Damage vs. Resolution? Front Cardiovasc Med. 2019;6:25.

14. Petković F, Castellano B. The role of interleukin-6 in central nervous system demyelination. Neural Regen Res. 2016;11(12):1922-3.

15. Feng Q, Wang YI, Yang Y. Neuroprotective effect of interleukin-6 in a rat model of cerebral ischemia. Exp Ther Med. 2015;9(5):1695-701.

16. Okazaki K, Kuboi T, Kusaka T, Kondo M, Kimura H. Pathophysiological Roles of Cytokines in the Brain During Perinatal Asphyxia. Ann Pediatr Child Health. 2015;3(1):1-10. 
17. Helsinki WMADo. Recommendations guiding physicians in biomedical research involving human subjects 1996 [Available from: https://www.wma.net/wpcontent/uploads/2016/11/DoH-Oct1996.pdf.

18. Chiesa C, Pellegrini G, Panero A, De Luca T, Assumma M, Signore F, et al. Umbilical cord interleukin-6 levels are elevated in term neonates with perinatal asphyxia. Eur $\mathbf{J}$ Clin Invest. 2003;33(4):352-8.

19. Bharathi B, Bhat BV, Negi VS, Adhisivam B. Inflammatory mediators as predictors of outcome in perinatal asphyxia. Indian J Pediatr. 2015;82(5):4338.

20. Bhalala US, Koehler RC, Kannan S. Neuroinflammation and neuroimmune dysregulation after acute hypoxic-ischemic injury of developing brain. Front Pediatr. 2014;2:144.

21. McAdams RM, Juul SE. The Role of Cytokines and Inflammatory Cells in Perinatal Brain Injury. Neurology Research International. 2012;2012:561494.

22. Yang XL, Wang X, Shao L, Jiang GT, Min JW, Mei $\mathrm{XY}$, et al. TRPV1 mediates astrocyte activation and interleukin-1beta release induced by hypoxic ischemia (HI). J Neuroinflammation. 2019;16(1):114.

23. Ahearne CE, Chang RY, Walsh BH, Boylan GB, Murray DM. Cord Blood IL-16 Is Associated with 3-Year Neurodevelopmental Outcomes in Perinatal Asphyxia and Hypoxic-Ischaemic Encephalopathy. Dev Neurosci. 2017;39(1-4):59-65.

24. Chalak LF. Inflammatory Biomarkers of Birth Asphyxia. Clin Perinatol. 2016;43(3):501-10.

25. Nũ nez A, Benavente I, Blanco D, Boix HCn, F., Chaffanel M, Fernández-Colomerg $\mathrm{B}$, et al. Oxidative stress in perinatal asphyxia and hypoxicischaemic encephalopathy. An Pediatr (Barc). 2018;88:228.e1-.e9.

26. Koehler RC, Yang ZJ, Lee JK, Martin LJ. Perinatal hypoxic-ischemic brain injury in large animal models: Relevance to human neonatal encephalopathy. J Cereb Blood Flow Metab. 2018;38(12):2092-111.
27. Ginet V, Pittet MP, Rummel C, Osterheld MC, Meuli $\mathrm{R}$, Clarke PG, et al. Dying neurons in thalamus of asphyxiated term newborns and rats are autophagic. Ann Neurol. 2014;76(5):695-711.

28. Boskabadi H, Maamouri G, Tavakkol Afshari J, Zakerihamidi M, Kalateh Molaee M, Bagheri F, et al. Combination of Serum Interleukin- $1 \beta$ and 6 Levels in the Diagnosis of Perinatal Asphyxia. Archives of Iranian medicine. 2016;19(5):312-6.

29. Paliwal P, Varma M, Mulye S, Paliwal M, Shaikh M. Study of Neurological Marker in Perinatal Asphyxia and Its Correlation with Different Stages of Hypoxic Ischemic Encephalopathy. International Journal of Scientifi c Study. 2014;2(7):40-3.

30. Procianoy RS, Silveira RC. The role of sample collection timing on interleukin-6 levels in earlyonset neonatal sepsis. J Pediatr (Rio J). 2004;80(5):407-10.

31. Wagdy E-S, Hasan E, Eman E. Interleukin-1 $\beta$ in perinatal asphyxia. Benha Medical Journal. 2016;33(2).

32. Bajnok A, Berta L, Orbán C, Veres G, Zádori D, Barta $\mathrm{H}$, et al. Distinct cytokine patterns may regulate the severity of neonatal asphyxia-an observational study. J Neuroinflammation. 2017;14(1):244.

33. Varsami M, Xanthos T, Aroni F, Argyri I, Lelovas P, Dontas I, et al. Inflammation and oxidative stress biomarkers in neonatal brain hypoxia and prediction of adverse neurological outcome: a review. Journal of Pediatric and Neonatal Individualized Medicine. 2013;2(2):1-14.

34. Neira-Pena T, Rojas-Mancilla E, Munoz-Vio V, Perez R, Gutierrez-Hernandez M, Bustamante D, et al. Perinatal asphyxia leads to PARP-1 overactivity, p65 translocation, IL-1beta and TNF-alpha overexpression, and apoptotic-like cell death in mesencephalon of neonatal rats: prevention by systemic neonatal nicotinamide administration. Neurotox Res. 2015;27(4):453-65.

35. Aly H, Khashaba MT, El-Ayouty M, El-Sayed O, Hasanein BM. IL-1beta, IL-6 and TNF-alpha and outcomes of neonatal hypoxic ischemic encephalopathy. Brain Dev. 2006;28(3):178-82. 